\title{
Diagnostic efficiency of paramedical workers in leprosy
}

\author{
ASHOK KUMAR, V DURAI, \\ N SIVAPRASAD \& P SIRUMBAN \\ Division of Epidemiology and Statistics, Central Leprosy Teaching \\ and Research Institute, Chingleput (TN), India
}

Accepted for publication 26 March 1985

Summary The diagnostic efficiency of 9 paramedical workers trained in leprosy was assessed with regard to the misdiagnoses and wrong diagnoses made by them during their involvement in a recent leprosy case detection (survey) programme. The workers missed (misdiagnosed) 10.5 leprosy cases per thousand persons examined by them during the survey. Of the 316 new cases detected by workers, 55 $(17.4 \%)$ were wrongly diagnosed as leprosy, mostly non-lepromatous $(\mathrm{N})$ type. Amongst the correctly diagnosed cases, $98 \% \mathrm{~N}$-type cases were correctly classified by them; 3 out of $9(33 \%)$ borderline-tuberculoid (BT) cases were over-diagnosed as borderline lepromatous (BL) type. The clinical activity status of $39(16.3 \%)$ out of 240 leprosy cases, all $\mathrm{N}$-type, was either over-assessed as active $(11.7 \%)$ or under-assessed as inactive $(4 \cdot 6 \%)$.

The implications, and suggestions to improve the technical skills of workers to achieve optimal efficiency in their work, are discussed.

\section{Introduction}

Since leprosy case detection depends on the diagnostic efficiency of paramedical workers (PMWs) employed in the programme, their training and technical skills should be kept up-to-date for effective leprosy control. One study ${ }^{1}$ has assessed the diagnostic efficiency of trained PMWs engaged in the 7th total population survey (Jan 1981-June 1982) in a part of Chingleput District, of Tamil Nadu, India, and extended suggestions to improve their diagnostic efficiency. This operational research project was carried over to the next population survey, ie the 8th total (July 1982-July 1983), of the same area, to study: 1, the quantum of leprosy patients being missed (misdiagnosis) by PMWs during the survey; and 2, their efficiency in diagnosis and classification of leprosy cases newly detected by them during the survey.

\section{Materials and methods}

Nine trained and experienced (5-20 years) PMWs examined about $94 \%$ of 85,000 
persons during the total population survey (July 1982-July 1983) of 52 villages in Chingleput District. Most of these villages are thickly populated and well connected with roads. During the last 7 surveys of this area by these workers, a very good rapport has been established with the community.

A total of 630 new cases were recorded during the 8th survey period of that area. Of these 630 new cases, only 316 untreated patients could be re-examined and confirmed by an experienced medical officer within 3-4 months of their detection by workers. The remaining 314 cases were not included in the present study on account of 1 , their non-availability for confirmation (69); 2, diagnosis by another medical officer in a mobile treatment unit on their voluntary reporting (30); and 3, inclusion of cases in a chemotherapeutic trial after confirmation by other doctors (215). Presuming the diagnosis of the Medical Officer to be correct, the diagnostic efficiency of PMWs was thus assessed on those 316 cases newly detected by them and confirmed by the same Medical Officer.

For estimating the number of leprosy cases being missed (misdiagnosed) by workers during the survey, all the persons reported free from leprosy (healthy) by 9 PMWs during 13 days' (randomly selected) survey of their respective areas on different dates were re-examined within 2-3 days by an experienced medical officer (MO). Of the total 879 persons examined by PWMs (67 persons/PMW/ day), 809 were reported to be free from leprosy (healthy). Out of these 809 healthy persons, only 667 could be re-examined by the medical officer as others were not available. The missing case rate (MCR) was thus estimated on these 667 persons with the help of the following formula:

$$
\mathrm{MCR}=\begin{gathered}
\text { No. of leprosy cases detected by medical officer } \\
\text { No. of persons reported free from leprosy by PMWs } \\
\text { and re-examined by medical officer }
\end{gathered} \times 100
$$

\section{Results}

MISDIAGNOSIS OF LEPROSY BY PMWS

On re-examination of 667 persons reported free from leprosy by PMWs, the Medical Officer on clinical evidence diagnosed (detected) 7 active cases of leprosy (Table 1) thereby indicating a MCR of $1.05 \%$, i.e. 10.5 cases missed per thousand persons examined by workers. It could be said that these 7 cases were overlooked by workers during the survey.

\section{PMWS' EFFICIENCY IN DIAGNOSIS AND CLASSIFICATION OF LEPROSY}

Of the total of 316 new cases detected by PMWs, $55(17.4 \%)$ were wrongly diagnosed as leprosy, mostly non-lepromatous (N) type (Table 2). Wrong diagnosis was most common in children. All these 55 wrongly diagnosed cases, 
Table 1. Leprosy cases misdiagnosed by PMWs

\begin{tabular}{|c|c|c|c|c|c|}
\hline $\begin{array}{l}\text { Sl. } \\
\text { No. }\end{array}$ & & $\begin{array}{l}\text { ge }(y r) \\
\text { d sex }\end{array}$ & $\begin{array}{l}\text { Type of } \\
\text { leprosy }\end{array}$ & Site of lesion & Remarks \\
\hline 1 & 37 & Male & PN & LP nerve (left) & \multirow{3}{*}{$\begin{array}{l}\text { (i) All cases of pure neuritic leprosy had } \\
\text { mild to moderate thickened and tender LP } \\
\text { nerves with below knec area of anaesthesia, } \\
\text { for duration of } 01-03 \text { years. }\end{array}$} \\
\hline 2 & 20 & Male & PN & $\begin{array}{l}\text { LP nerve (left) and left } \\
\text { post. and ant. tibial } \\
\text { nerves }\end{array}$ & \\
\hline 3 & 18 & Male & PN & LP nerve (right) & \\
\hline 4 & 39 & Male & I & Scapular region (left) (ii) & \multirow{4}{*}{$\begin{array}{l}\text { All cases of indeterminate leprosy showed } \\
\text { impairment of fine touch and pinprick pain } \\
\text { sensations on their single patch }(1-1.5 \mathrm{~cm} \\
\text { diameter }) \text { of } 4-5 \text { months duration. }\end{array}$} \\
\hline 5 & 32 & Female & I & $\begin{array}{l}\text { Right lumbar region } \\
\text { (back) }\end{array}$ & \\
\hline 6 & 24 & Female & I & Right cheek & \\
\hline 7 & 3 & Male - & I & Left lat. abdomen & \\
\hline
\end{tabular}

PN, pure neuritic; I, early indeterminate; LP, lateral popliteal nerve

Table 2. PMWs' efficiency in leprosy diagnosis

\begin{tabular}{lccc}
\hline \multicolumn{1}{c}{ Diagnosis by PMWs } & $\mathrm{N}$ & $\mathrm{N}$ ? & Total \\
\hline Correct diagnosis & 246 & 9 & 255 \\
& $(80 \cdot 39 \%)$ & $(90 \cdot 00 \%)$ & $(80 \cdot 70 \%)$ \\
Wrong diagnosis as leprosy & $\begin{array}{c}54 \\
(17.65 \%)\end{array}$ & $\begin{array}{c}1 \\
(10 \cdot 00 \%)\end{array}$ & $\begin{array}{c}(17 \cdot 40 \%) \\
6\end{array}$ \\
$\begin{array}{l}\text { Suspected by MO as } \\
\text { having leprosy }\end{array}$ & $(1.96 \%)$ & - & $(1.90 \%)$ \\
\hline Total & 306 & 10 & 316 \\
\hline
\end{tabular}

Note. All the above N?L cases were borderline-tuberculoid (BT) type, and there was no case of lepromatous (L) type.

mostly children ( $>60 \%$ ), had fungal, malnutritional and skin lesions other than leprosy.

Of the 246 non-lepromatous cases correctly diagnosed by workers, 240 $(97.6 \%)$ were also correctly classified; however, 3 out of $9(33.3 \%)$ N?L (BT) cases were over-diagnosed as borderline-lepromatous (BL) type (Table 3(a)). The bacteriological examination by slit skin smear technique was carried out on all the N?L cases on the day of their detection by the workers themselves. All these cases showed bacterial negativity, which was not made known to the Medical Officer who re-examined these cases.

Although the activity status of all N?L type lesions was assessed correctly by 
Table 3(a). PMW' efficiency in classification (types) of leprosy lesions

\begin{tabular}{|c|c|c|c|c|}
\hline \multicolumn{2}{|c|}{ Classification by PMWs } & $\mathrm{N}$ & N?L & Total \\
\hline \multicolumn{2}{|r|}{ Correct } & $\begin{array}{c}240 \\
(97 \cdot 56 \%)\end{array}$ & $\begin{array}{c}6 \\
(66.67 \%)\end{array}$ & $\begin{array}{c}246 \\
(96.47 \%)\end{array}$ \\
\hline \multirow{2}{*}{ Wrong* } & Over-diagnosis & - & $\begin{array}{c}3 \\
(33 \cdot 33 \%)\end{array}$ & $\begin{array}{c}3 \\
(1 \cdot 18 \%)\end{array}$ \\
\hline & Under-diagnosis & $\begin{array}{c}6 \\
(2 \cdot 44 \%)\end{array}$ & - & $\begin{array}{c}6 \\
(2 \cdot 35 \%)\end{array}$ \\
\hline . & Total & 246 & 9 & 255 \\
\hline
\end{tabular}

* Over-diagnosis, mild type being classified as severe type. Under-diagnosis, severe type being classified as mild typc.

Table 3(b). PMW' efficiency in classification (activity status) of leprosy lesions

\begin{tabular}{ccccc}
\hline Activity status by PMWs & $\mathrm{N}$ & $\mathrm{N} ? \mathrm{~L}$ & Total \\
\hline Correct & $\begin{array}{c}197 \\
(83.47 \%)\end{array}$ & $\begin{array}{c}04 \\
(100 \%)\end{array}$ & $\begin{array}{c}201 \\
(83.75 \%)\end{array}$ \\
\hline \multirow{2}{*}{ Wrong* } & Over-assessment & $\begin{array}{c}28 \\
(11.86 \%)\end{array}$ & - & $\begin{array}{c}28 \\
(11 \cdot 67 \%)\end{array}$ \\
\cline { 2 - 5 } & Under-assessment & $\begin{array}{c}11 \\
(4.66 \%)\end{array}$ & - & $\begin{array}{c}11 \\
(04.58 \%)\end{array}$ \\
\hline Total & & 236 & 04 & 240 \\
\hline
\end{tabular}

Note. Since no information on activity status was provided by PMWs on $10 \mathrm{~N}$ and $5 \mathrm{~N}$ ? L (total 15 cases), they were excluded.

* Over-assessment, inactive lesions assessed as active, and underassessment, active lesions assessed as inactive. 
PMWs, 39 out of $236(16.52 \%) \mathrm{N}$-type lesions were either over-assessed as active $(11.86 \%)$ or under-assessed as inactive $(4.66 \%)$ (Table $3(b))$.

The above cross-sectional observations are almost similar to our experiences reported earlier. ${ }^{\prime}$

\section{Discussion}

The misdiagnosis of leprosy was most common in young adult males, perhaps due to hurry and lack of interest and motivation amongst both the PMWs and persons (patients) resulting in improper clinical examination by the worker(s) ignoring standard methods and criteria. On the other hand, the wrong diagnosis was more frequent in children, possibly due to the workers' insufficient knowledge, training and skills to differentiate other common skin lesions from early leprosy. The extra-leprosy-consciousness while working in a high endemic area could also lead to wrong/over diagnosis by workers, as experienced earlier, ' that out of the total of 215 persons suspected of having leprosy by workers, only $75(35 \%)$ were found to be suffering from leprosy and the remainder had no evidence of disease when re-examined by a medical officer. Moreover, the inadequate qualitative supervision and assessment of PMWs' work could adversely influence their efficiency. It is needless to point out that poor diagnostic efficiency of workers has considerable implications on patients for their treatment, the community for transmission of disease, and on the leprosy programme as such.

As emphasized in another study the diagnostic efficiency of workers can be appreciably improved by constant good quality of training, supervision, and evaluation of their work by motivated and experienced medical officers. It is felt necessary that the workers should be equipped with a suitably designed manual highlighting the policy and operational methodology guidelines to carry out their work uniformly, efficiently and effectively. In order to quantify the misdiagnosis and wrong diagnosis of leprosy by workers, about $5-10 \%$ of the surveyed population should be regularly counter-checked by the non-medical supervisors concerned; and also by the medical officer(s) during their supervisory visits to the area. All the cases detected by the workers should be concurrently confirmed by experienced medical officers in their respective units, then only a list of the known cases should be prepared and reported to higher levels for meaningful planning and evaluation of the leprosy situation and control programme. The delayed case confirmation may slightly inflate the figure of wrong diagnosis by PMWs as a proportion of early leprosy lesions may self-heal in the course of time.

Another important relevant point which needs to be mentioned is that although the PMWs form the pillars of our National Leprosy Programme(s), their involvement in planning and decision making has been quite passive and opportunities for their better prospects while in jobs have been limited. In 


\section{Ashok Kumar et al.}

addition to various administrative and social aspects, the above factors are to a large extent responsible for their reducing interest, motivation and efficiency in leprosy work. To look into various problems of workers and to gather and utilize their valuable field experiences for planning, as well as to allow them to benefit from each other's knowledge and experience; the active involvement of peripheral workers in local/state/national level workshops should be of paramount importance to improve the overall efficiency and effectiveness of the leprosy programme. Likewise to sustain their interest in leprosy work, their job prospects could be enhanced by opening at'least 3 promotional avenues, i.e. Non-medical Supervisor, Assistant and Deputy Leprosy Control Unit Officers, with appropriate training before each promotion to the deserving candidates. Now is the time to consider these aspects when we are aiming to eradicate leprosy by the end of this century.

\section{Acknowledgments}

This project was carried out under 'ICMR Unit for special studies in leprosy' attached to our Institute. The statistical assistance of Mr R Perumal (computer) and secretarial assistance of $\mathrm{Mr}$ T Sridharan (senior stenographer) and Kumari $\mathrm{K}$ Eswari, is thankfully acknowledged.

\section{Reference}

I Ashok Kumar, Durai V, Sirumban P. Diagnostic efficiency of paramedical workers involved in leprosy case detection programme. Ind J Lepr, 1984; 56 (3): 626-32. Also, Paper read in XII International Leprosy Congress, New Delhi, February 1984 (Abstract no. 359). 